\title{
Preclinical Trial of Traditional Plant Remedies for the Treatment of Complications of Gestational Malaria
}

\author{
Peter Uchenna Amadi ${ }^{1, *(1)}$, Emmanuel Nnabugwu Agomuo ${ }^{1}$, Chinyere Nneka Ukaga ${ }^{2}$, Uche Chinedu Njoku ${ }^{3}$, \\ Joy Adaku Amadi ${ }^{4}$ and Chinweuba Godswill Nwaekpe ${ }^{5}$ \\ 1 Department of Biochemistry, Imo State University, Owerri 460102, Nigeria; Nnabugwuago@gmail.com \\ 2 Department of Animal and Environmental Biology, Imo State University, Owerri 460102, Nigeria; \\ chinyukaga@yahoo.com \\ 3 Department of Biochemistry, University of Port Harcourt, Choba 500102, Nigeria; \\ Uche_njoku@uniport.edu.ng \\ 4 Department of Nutrition and Dietetics, Imo State University, Owerri 460102, Nigeria; \\ Joyevans2020@gmail.com \\ 5 Department of Biochemistry, Federal University of Technology, Owerri 460102, Nigeria; \\ Nwaekpe.chinweuba@futo.edu.ng \\ * Correspondence: peter_amadi@uniport.edu.ng or Amadi@imsu.edu.ng
}

check for updates

Citation: Amadi, P.U.; Agomuo, E.N.; Ukaga, C.N.; Njoku, U.C.; Amadi, J.A.; Nwaekpe, C.G. Preclinical Trial of Traditional Plant Remedies for the Treatment of Complications of Gestational Malaria. Medicines 2021, 8, 79. https:// doi.org/10.3390/medicines8120079

Academic Editors: James David Adams and Basil D. Roufogalis

Received: 27 October 2021

Accepted: 14 December 2021

Published: 17 December 2021

Publisher's Note: MDPI stays neutral with regard to jurisdictional claims in published maps and institutional affiliations.

Copyright: (c) 2021 by the authors. Licensee MDPI, Basel, Switzerland. This article is an open access article distributed under the terms and conditions of the Creative Commons Attribution (CC BY) license (https:// creativecommons.org/licenses/by/ $4.0 /)$.

\begin{abstract}
Background: Most pregnant women living in high malaria endemic regions of Nigeria use herbal remedies for the management of malaria-in-pregnancy, rather than the commonly prescribed drugs. Remedies common to this area involve a suspension of $A$. indica (AI) leaves and in some cases, a suspension containing a mixture of $\mathrm{AI}$ and D. edulis (PS). Aim: This study examined the therapeutic efficacies of AI, PS, or a combination of AI and PS in a pregnant rat model for exoerythrocytic stages of Plasmodium falciparum parasite. Method: A predetermined sample size of 30 dams was used (for a power level and confidence interval of 95\%), and divided equally into six groups made up of non-malarous dams, untreated malarous dams, and malarous dams either treated exclusively with $1 \mathrm{~mL}$ of $3000 \mathrm{mg} / \mathrm{kg}$ b.w AI, $1000 \mathrm{mg} / \mathrm{kg}$ b.w PS, AI + PS (50\% v/v), or $25 \mathrm{mg} / \mathrm{kg}$ b.w CQ. Result: No maternal mortality was recorded. AI significantly improved maternal weight gain from 32.4 to $82.2 \mathrm{~g}$ and placental weight from 0.44 to $0.53 \mathrm{~g}$. In the curative test, $\mathrm{AI}$ and $\mathrm{AI}+\mathrm{PS}$ significantly reduced the average percentage parasitemia (APP) in the pregnant rats from $>80 \%$ to $<20 \%$. No significant difference in the APP was found between the pregnant rats treated with any of CQ or AI during the suppressive test. Results for the prophylactic test of the study groups showed that the APP was significantly reduced from $24.69 \%$ to $3.90 \%$ when treated with AI and $3.67 \%$ when combined with PS. $\mathrm{AI}+\mathrm{PS}$ reduced diastolic blood pressure from 89.0 to $81.0 \mathrm{~mm} / \mathrm{Hg}$ and compared with that of the non malarous dams. AI or AI + PS significantly increased the platelet counts $\left(10^{3} \mu \mathrm{L}\right)$ from 214.1 to 364.5 and 351.2, respectively. AI and AI + PS improved birth weight from 2.5 to $3.9 \mathrm{~g}$ and crown rump length from 2.6 to $4.1 \mathrm{~cm}$. For biomarkers of preeclampsia, combining AI and PS led to the reversal of the altered levels of creatine kinase, lactate dehydrogenase, cardiac troponin, soluble Fms-Like Tyrosine Kinase-1, and placental growth factor. Conclusions: This study validates the use of $A$. indica for the treatment of gestational malaria due to its antiplasmodial and related therapeutic effects and in combination with pear seeds for the management of malaria-in-pregnancy-induced preeclampsia.
\end{abstract}

Keywords: malaria; parasitemia; pregnancy; preeclampsia; Azadirachta indica; Dacryodes edulis

\section{Introduction}

Malaria is a leading cause of deaths in low- and middle-income countries (LMICs) and a significant worldwide public health concern [1,2]. In Nigeria, malaria is a major cause of illness, maternal and fetal losses, low birth weight (LBW), and poverty, and threatens the economy and wellbeing of the nation. Approximately a $\$ 12$ billion annual loss is incurred to manage the economic burden of malaria in Africa [3]. In these high endemic 
regions, pregnant women and children below 5 years are of particular public health interest because they constitute the category with the highest risk for malaria-related morbidity and mortality [4]. In 2018, about 11 million pregnancies in moderate and high transmission SubSaharan African (SSA) countries were exposed to malaria infection, with Nigeria and DRC Congo having the highest prevalence to exposure [5]. Another study reported that malaria accounts for $70 \%$ of maternal morbidity in Nigeria, $15 \%$ of maternal anemia, and $5-14 \%$ of low birth weight, with the majority of these pregnant women predicted to have two to three episodes during a particular pregnancy, four times likely to get sick from malaria, and twice likely to die from the disease [6]. Problems of implementation and effectiveness of interventions have contributed to the small margin of success achieved from these programs. In the majority of studies, malaria endemic regions are inaccessible and noncompliant with malaria action programs, while the majority of these women have no access to primary healthcare facilities, and worse still, a greater proportion of pregnant women rely on traditional medicine practitioners for ante-natal care, delivery, and postnatal care. African traditional medicine remains one of the oldest and most adopted forms of medical care delivery. The affordability, perceived efficacy, and being the most widely accepted and culturally deep-rooted tradition among Africans are primary reasons behind the high prevalence of traditional medicine use in poor-resource settings. A study on mutigravids in malaria endemic regions of Nigeria has indicated the effectiveness and suitability of herbal medicine and not due to financial constraint or lack of access to a health facility as reasons for the preference over conventional treatments [7]. Another study reported that $93 \%$ of pregnant women within 3 other malaria endemic regions of Nigeria exclusively used herbal medicine for gestational malaria, and $87.1 \%$ of these women perceived herbal medicine as effective for treating malaria [8]. It is therefore long overdue to exploit and refine these age-long treatment protocols peculiar to these areas of high malaria endemicity to support the goal of reducing the incidence of malaria-in-pregnancy in poor-resource settings. To this effect, we stratified the response of pregnant women living in areas of high malaria endemic regions of Imo State, regarding the predominant traditional practice of malaria treatment for gestational malaria, and found A. indica therapy had the highest prevalence. Azadirachta indica plants popularly known as the neem tree belong to the family of Meliaceae and have a very long-recorded wide reportage for its diverse medicinal use in the tropics, especially for malaria treatment [9-11] and as a potent antioxidant, anticancer, anti-inflammatory, and antidiabetic agent [12,13]. Nimbolide [9] and genudin [14] are the reported most bioactive components against $P$. falciparum and in one in vitro study, the limonoids from $A$. indica produced an $\mathrm{IC}_{50}$ of $0.95 \mathrm{pg} / \mathrm{mL}$ against $P$. falciparum [15]. These early studies on A. indica in addition to the evidence of use during pregnancy in real life in endemic regions of Nigeria encourages further studies. The aim of this present study was to use a pregnant rat model for the exoerythrocytic stages of the Plasmodium falciparum malaria parasite to verify the antimalarial effect of $A$. indica supplemented with $D$. edulis seeds as used in real life during malaria-in-pregnancy, and compared to chloroquine-treated and non-malarous controls.

\section{Methodology}

Thirty-five (35) pregnant women in Owerri North Imo State Nigeria were issued a questionnaire seeking information about traditional antimalarial methods used during gestation. Their responses were stratified and the most popular herb with a $64 \%$ prevalence taken as aqueous extract was identified as Azadirachta indica. Approximately $11 \%$ identified the seeds of $D$. edulis as an additional herb to control incidences of hypertension during malarous pregnancies. As justification, we initially ascertained the vasomodulatory potentials of D. edulis seeds [16]; hence, we decided to apply a combinatorial administration of both therapies to malarous dams. 


\subsection{Sample Collection and Preparation}

Fresh leaves of Azadirachta indica (neem) and ripe fruits of D. edulis were obtained from a farmland at Imo State University, and identified by Prof. F.N. Mbagwu at the Department of Plant Science and Biotechnology, Imo State University Owerri. The leaves and fruits were thoroughly washed with distilled water to remove debris and air dried. The pear fruits were boiled and afterwards cut open to harvest seeds. Precisely $50 \mathrm{~g}$ of each sample were ground using a mechanical grinder and soaked in $100 \mathrm{~mL}$ of distilled water for $24 \mathrm{~h}$. The aqueous extract of each sample was concentrated using a rotary evaporator. An acute toxicity test was carried out according to the procedure of Amadi et al. [17] to determine the LD50 of the samples on pregnant rats and was found at $1500 \mathrm{mg} / \mathrm{kg}$ for D. edulis and $3500 \mathrm{mg} / \mathrm{kg}$ for $A$. indica.

\subsection{Sample Size Determination}

The sample size for this study was calculated using the $G^{*}$ Power statistical software 3.1.9.7 with data from our pilot study measuring blood schizonticidal activity as the primary outcome. The pilot study compared the blood schizonticidal activity of $A$. indica, $D$. edulis, and both mixtures on malarous rats with malarous rats treated with chloroquine. The standard deviation within each group $(\sigma)$, otherwise known as the combined standard deviation, was estimated at $34.0415 \%$. With these details, the effect size (f) was automatically generated as 0.9754114 with the $G^{*}$ Power statistical software. We decided to be maximally idealistic and chose $\alpha=\beta=0.05$, implying a power level of $1-\beta=0.95$ (95\%) and at a $95 \%$ significance level, a sample size of 25 experimental rats was estimated using the statistical tool and with a similar group size for non-malarous dams, a total of 30 pregnant (30) rats were required for this study.

\subsection{Animal Handling}

The animal handling completely aligned with the Principles of Laboratory Animal Care (NIH Publication No. 85-23). Ethical permit for this study was issued by the Biochemistry Research and Ethics Board, Imo State University (IMSU/BCM/ETS/20181212). Precisely 20-week-old inbred adult non-pregnant female rats, and 16-week-old adult rats were used for this study. The weights of male rats were from $150-180 \mathrm{~g}$ while female rats were from 190-220 g. Vaginal lavage was used for the determination of the female estrous cycle in the rats and afterwards, the rats were separated and housed overnight in different metabolic cages of 3 female rats to 1 male rat at the time of mating. Normal rat feed pellets (UAC Nigeria Grand Cereals Vital Feeds, Jos, Plateau State, Nigeria) and water ad libitum were provided. The female rats were tested daily for copulation and a positive vaginal smear check/mating plug confirmed pregnancy and served as the first day of gestation (G0). Thirty pregnant rats were selected and housed individually in metabolic cages with suitable bedding.

\subsection{Inoculation of Pregnant Rats}

Inoculums consisting of $5 \times 10^{7}$ infected erythrocytes were obtained from donor rats previously infected with Plasmodium falciparum strains NF54. The P. falciparum strain was rat-adapted from a mouse strain by three successive 4-week passages through 7-week-old rats [18]. Parasitemia of the donor's blood was first determined at $81 \%$. The inoculums were diluted with $0.9 \%$ physiological saline and red blood cells of uninfected rats to obtain $1 \times 10^{7}$ P. falciparum-infected erythrocytes. Twenty-five pregnant rats were inoculated intravenously with $0.2 \mathrm{~mL}$ inoculums of the diluted infected erythrocytes and confirmed $3 \mathrm{~h}$ later by microscopy using the tail blood of the rats. The day of inoculation was defined as day zero (D0).

\subsection{Grouping, Feeding, and Sample Collection}

The experimental animals were divided into 6 study groups: group 1 was the negative control (-ve ctrl) representing the untreated malarous dams, group 2 (inf $+\mathrm{CQ}$ ) was the 
malarous dams treated with $25 \mathrm{mg} / \mathrm{kg}$ chloroquine, group 3 (inf $+\mathrm{AI}$ ) was the malarous dams treated with $3000 \mathrm{mg} / \mathrm{kg}$ b.w A. indica, group 4 (inf + PS) was the malarous dams treated with $1000 \mathrm{mg} / \mathrm{kg}$ b.w pear seed extracts, group 5 (inf $+\mathrm{AI}+\mathrm{PS}$ ) was the malarous dams treated with $50 \%$ v/v of $3000 \mathrm{mg} / \mathrm{kg}$ b.w A. indica and $1000 \mathrm{mg} / \mathrm{kg}$ b.w pear seeds, and group 6 (baseline) was the non-malarous dams. All treatments were made by oral gavaging with $1 \mathrm{~mL}$ of the test compounds administered once daily. All rats had free access to normal rat chow and water.

Treatment lasted for 21-23 days until parturition.

\subsection{Measurement of Maternal Hemodynamics, Pregnancy Outcomes, and Sample Collection}

Maternal weight before copulation and prior to delivery was recorded using sensitive digital weighing balance, as was the feed intake. Urine output was collected on gestation day 19, and measured with a Thermo Fisher Scientific, Inc. (Waltham, MA, USA). Pierce ${ }^{\mathrm{TM}}$ BCA protein assay kit [19]. The pups were counted according to live and still born, weighed using the digital weighing balance, measured for crown rump length with Vernier calipers, and monitored for time taken for eye opening, and appearance of furs.

The blood pressure and heartbeat rate were measured using the tail cuff-based methods with a CODA non-invasive blood pressure (NIBP) system (Kent Scientific Corporation, Torrington, CT, USA). The platelet count was determined with the BC-2600 model of haematology autoanalyzer (Shenzhen Mindray Bio-medical Electronics, Shenzhen, China) according to the user manual.

Maternal blood $(3 \mathrm{~mL})$ was collected with a $5 \mathrm{~mL}$ disposable syringe immediately after delivery by cardiac puncture. The rats were first anesthetized with $3 \%$ intraperitoneal pentobarbital sodium (50 mg/kg). Animals were then sacrificed via exsanguination, and an autopsy was carried out to remove and weigh the placenta using a sensitive digital weighing balance. Serum was prepared by centrifugation of the blood samples at $4000 \mathrm{rpm}$ for $10 \mathrm{~min}$, transferred into a tube, and freeze-stored at $20{ }^{\circ} \mathrm{C}$ pending analysis.

\subsection{Determination of Antimalarial Activity}

For the antimalarial assay, a separate experimental set up involving 40 pregnant rats equally divided across the four test groups were used to evaluate the prophylactic and suppressive potentials of the chloroquine, exclusive $A$. indica, and D. edulis, administration, and a combined $A$. indica and D. edulis treatment.

The Rane's test was performed according to the method described by Ryley and Peters, [20] to determine the curative effects of the test compounds. The chemosuppressive potentials of the test compounds against the P. falciparum infectio were determined using the Peter's four-day suppressive test [21] while the prophylactive effect of the test compounds was determined according to the description of Peters [22]. The rectal temperature was measured using a digital rectal thermometer. The average percentage parasitemia, and suppression were calculated as follows [23]:

$$
\begin{gathered}
\% \text { Parasitemia }=\frac{\text { Number of parasitized RBC }}{\text { Total number of RBC count }} \times 100 \\
\% \text { Suppression }=\frac{\% \text { Parasitemia in negative control }-\% \text { Parasitemia in study group }}{\% \text { Parasitemia in negative control }} \times 100
\end{gathered}
$$

\subsection{Clinical Chemistry}

An enzymatic method according to the procedures in the Sigma-Aldrich assay kits were used for the determination of total cholesterol (TC), triglycerides (TGs), and high density lipoprotein cholesterol (HDL) with a BT-3000 auto analyzer (Biotecnica Instruments, Licenza, 18-00156 Rome Italy). Low-density lipoprotein (LDL), cardiac risk ratio (CRR), and atherogenic coefficients (ACs) were calculated as follows [24]:

$$
\mathrm{LDL}=\mathrm{TC}-\mathrm{HDL}-\mathrm{TG} / 5, \mathrm{CRR}=\mathrm{TC} / \mathrm{HDL}, \mathrm{AC}=\mathrm{CRR}-1
$$


Creatine kinase was assayed by spectrophotometry at an absorbance of $450 \mathrm{~nm}$ according to the assay protocol described by Horder et al. [25]. Lactate dehydrogenase was determined by enzymatic colorimetry using the methods described in the Lactate Dehydrogenase Kit (Sigma Aldrich St. Louis, MO, USA, Catalog No-MAK066) while the cardiac troponin test was performed by enzyme-linked immunosorbent assay (ELISA) in accordance with the procedures on the ELISA kit (East Biopharm, Hangzhou, Zhejiang, China). Soluble Fms-Like Tyrosine Kinase-1 (sFlt-1) and placental growth factor (PIGF) was determined by quantitative sandwich enzyme immunoassays using commercial ELISA kits from Mybiosource San Diego, CA, USA.

\subsection{Statistical Analysis}

The data obtained was analyzed and presented as the means \pm standard deviations of five determinations. A test of normality was performed on the data obtained before analysis using the Shapiro Wilk's Test to confirm the normality of the distribution of the values. An SPSS version 20 statistical tool was used for the computation of the means and standard deviations, and a test of significance at $95 \%$ confidence by One-Way Analysis of Variance (ANOVA) among the test groups. The degree of correlation between the Average Percentage Parasitemia (curative) and biomarkers of myocardial infarction and preeclampsia was analyzed using the Pearson's correlation function of the GraphPad Prism software version 7.04 (GraphPad Software, San Diego, CA, USA). The parameters represented graphically were performed with the GraphPad Prism software version 7.04.

\section{Results}

Table 1 shows the morphometric features of the malarous dams in the different study groups. No maternal mortality was recorded across the study groups. Without treatment, the feed intake of the malarous pregnant rats significantly reduced from 756.4 to $498.6 \mathrm{~g}$. When treated with chloroquine (CQ), a significant increase in feed intake up to $680 \mathrm{~g}$ was observed when compared to the untreated malarous dams while the malarous dams treated with Azadirachta indica (AI) significantly increased to $701.8 \mathrm{~g}$ compared with feed intake of the CQ-treated dams. The feed intake of the malarous dams treated with a combination of AI and pear seeds (PSs) was not significantly different from those of the non-malarous dams. The weight gain and placenta weight of the untreated malarous pregnancies were significantly lower than the treatment groups and baseline. Malarous dams treated with AI or combined with PS significantly increased the weights of the malarous dams compared to the baseline. PS administration increased the weights of the malarous rats comparably to the non malarous rats. The placenta weight of the untreated malarous dams was significantly lower than the non-malarous dams and the CQ-treated malarous dams. No significant difference was found between the placenta weight of the treatment groups and the baseline.

Table 1. Maternal characteristics of malarous dams in the different study groups.

\begin{tabular}{ccccc}
\hline Groups & Maternal Mortality (\%) & Feed Intake (g) & Weight Gain (g) & Placenta Weight (g) \\
\hline -ve ctrl & 0 & $498.6 \pm 18.7$ & $32.4 \pm 4.3$ & $0.44 \pm 0.02$ \\
Inf + CQ & 0 & $680.0 \pm 26.2$ & $75.6 \pm 4.8$ & $0.53 \pm 0.01$ \\
Inf + AI & 0 & $701.8 \pm 22.0^{\mathrm{a}}$ & $82.2^{\mathrm{a}} \pm 4.1^{\mathrm{c}}$ & $0.53 \pm 0.02^{\mathrm{c}}$ \\
Inf + PS & 0 & $632.6 \pm 30.8$ & $71.6^{\mathrm{c}} \pm 3^{\mathrm{c}}$ & $0.53^{\mathrm{c}} \pm 0.02^{\mathrm{c}}$ \\
Inf + AI + PS & 0 & $733.8 \pm 28.3^{\mathrm{b}}$ & $88.0 \pm 2.6$ & $0.54 \pm 0.03^{\mathrm{c}}$ \\
Baseline & 0 & $756.4 \pm 15.1$ & $76.8 \pm 5.9$ & $0.54 \pm 0.03$ \\
\hline
\end{tabular}

-ve ctrl-malarous dams untreated, inf + CQ-malarous dams treated with chloroquine, inf + AI-malarous dams treated with A. indica, inf + PS - malarous dams treated with pear seeds, inf + AI + PS - malarous dams treated with $A$. indica and pear seeds, baseline- non malarous rats, ${ }^{a}$-no significant difference $(p<0.05)$ with the chloroquine-treated malarous dams, ${ }^{\mathrm{b}}-$ no significant difference with the non malarous dams, ${ }^{c}$ - no significant difference with both the chloroquine-treated malarous dams and non malarous dams. 
Figure 1 shows the blood schizontocidal activities of $A$. indica (AI), pear seeds (PSs), and when combined, as compared to the effect of chloroquine (CQ) in the malarous dams. During the curative test, AI and when combined with PS significantly reduced the average percentage parasitemia (APP) in the pregnant rats from $>80 \%$ to $<20 \%$. The suppressive test showed a significantly reduced APP of up to $0.99 \%$ when the malarous dams were treated with AI or $4.7 \%$ when AI was combined with PS. No significant difference in the APP was found between the pregnant rats treated with CQ or AI. Results for the prophylactic test of the study groups showed that the APP was significantly reduced from $24.69 \%$ to $3.90 \%$ when treated with AI and 3.67\% when combined with PS. In comparison with the CQ-treated malarous dams, no significant difference was found with the AI and AI + PS-treated malarous dams. The exclusive treatment with PS produced $61 \%$ APP during the Rane's test, and 17.2\% and 18.3\%, respectively, with the suppressive and prophylactic tests. AI, PS, and AI + PS respectively produced up to $95.60 \%, 78.86 \%$, $30.89 \%$, and $79.49 \%$ average percentage suppression (APS) against $95.60 \%$ APS for CQ with the curative test, while each of AI and AI + PS produced $>85 \%$ APS in the suppressive test against 98\% APS for CQ, and 84.17\% and 85.12\% APS, respectively, during the prophylactic test, against $84.63 \%$ APS for CQ. PS-exclusive treatment achieved $49.10 \%$ and $25 \%$ APS, respectively, during the suppressive and prophylactic tests. Any of the AI or AI + PS treatments produced no significant change in the APS when compared to the CQ effect during the suppressive and prophylactic tests. The percentage decrease in the rectal temperature (RT) of the untreated malarous dams during the curative, suppressive, and prophylactic tests was 7.5\%,5.5\%, and 6.38\%, respectively. Across the three tests, CQ treatment significantly decreased the RT by $\leq 0.5 \%$; the AI treatment significantly decreased the RT by $1.72 \%, 1.60 \%$, and $1.95 \%$, respectively; while the AI + PS significantly decreased the RT by $\leq 1.1 \%$ and showed no significant difference with the CQ-treated group. The RT of the PS-treated group during the suppressive test remained similar to the untreated malarous dams.

The hemodynamics characteristics of the malarous and non-malarous dams are shown in Table 2. The untreated malarous dams showed significantly elevated systolic and diastolic BP, heartbeat rate, and urine protein elevation when compared with their respective baselines. The systolic and diastolic blood pressures of the treatment groups were comparable to the baseline. The heartbeat rates of the malarous dams treated with either exclusive PS or in combination with AI were comparable to the levels found for both the CQ-treated group and baseline. No significant difference was found between the urine protein excretion levels of the malarous dams treated with CQ and AI, while the group treated exclusively with PS showed comparable results to the baseline. Treatment with AI and in combination with PS showed that the platelet counts of both groups were significantly higher than the CQ-treated subjects and comparable to the baseline levels.

Table 2. Hemodynamics properties of malarous and non malarous dams.

\begin{tabular}{|c|c|c|c|c|c|}
\hline Groups & $\begin{array}{c}\text { Systolic BP } \\
\text { (mm/Hg) }\end{array}$ & $\begin{array}{c}\text { Diastolic BP } \\
(\mathrm{mm} / \mathrm{Hg})\end{array}$ & HBR (Beats/min) & 24 h Urine Protein Excretion (mg) & $\begin{array}{l}\text { Platelets Counts } \\
\quad\left(\times 10^{3} \mu \mathrm{L}\right)\end{array}$ \\
\hline -ve ctrl & $136.0 \pm 4.1$ & $89.0 \pm 2.2$ & $405.8 \pm 17.8$ & $0.83 \pm 0.03$ & $214.1 \pm 19.3$ \\
\hline $\operatorname{Inf}+\mathrm{CQ}$ & $122.0 \pm 2.7$ & $84.0 \pm 4.1$ & $332.0 \pm 8.6$ & $0.79 \pm 0.01$ & $314.6 \pm 20.4$ \\
\hline $\operatorname{Inf}+\mathrm{AI}$ & $123.0 \pm 2.7^{\mathrm{c}}$ & $83.0 \pm 2.7^{c}$ & $366.4 \pm 6.8$ & $0.77 \pm 0.01^{\mathrm{a}}$ & $364.5 \pm 14.9^{b}$ \\
\hline Inf + PS & $123.0 \pm 2.7^{\mathrm{c}}$ & $80.0 \pm 0.0^{c}$ & $319.6 \pm 5.7^{c}$ & $0.62 \pm 0.05^{b}$ & $249.9 \pm 17.0$ \\
\hline $\operatorname{Inf}+\mathrm{AI}+\mathrm{PS}$ & $122.0 \pm 2.7^{\mathrm{c}}$ & $81.0 \pm 2.2^{c}$ & $332.0 \pm 10.6^{c}$ & $0.67 \pm 0.02$ & $351.2 \pm 19.1^{b}$ \\
\hline Baseline & $122.0 \pm 2.7$ & $78.0 \pm 2.7$ & $321.6 \pm 6.0$ & $0.59 \pm 0.02$ & $356.6 \pm 26.9$ \\
\hline
\end{tabular}

-ve ctrl-malarous dams untreated, inf $+\mathrm{CQ}-$ malarous dams treated with chloroquine, inf $+\mathrm{AI}-$ malarous dams treated with $A$. indica, inf + PS-malarous dams treated with pear seeds, inf + AI + PS-malarous dams treated with A. indica and pear seeds, baseline-non malarous rats, ${ }^{\mathrm{a}}$-no significant difference $(p<0.05)$ with the chloroquine-treated malarous dams, ${ }^{\mathrm{b}}$-no significant difference with the non malarous dams, ${ }^{\mathrm{c}}$ - no significant difference with both the chloroquine-treated malarous dams and non malarous dams. 
CURATIVE

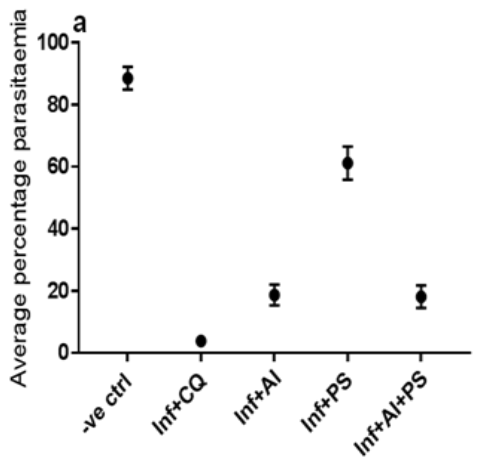

Experimental groups

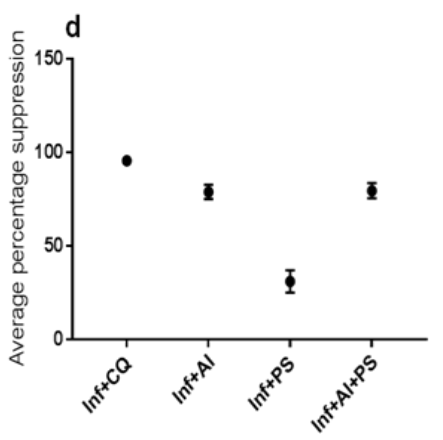

Experimental groups

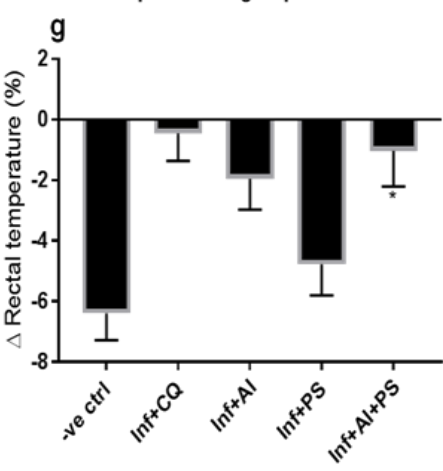

Experimental groups
SUPPRESSIVE

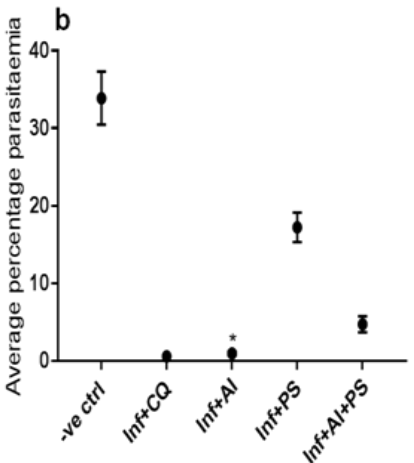

Experimental groups

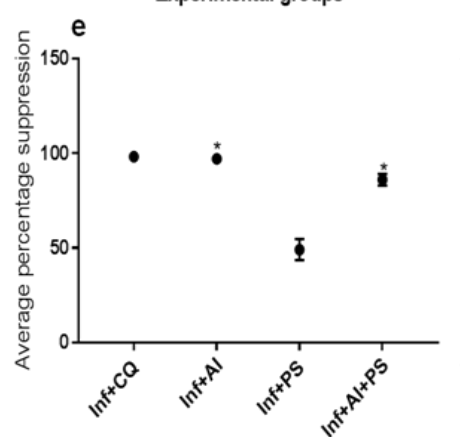

Experimental groups

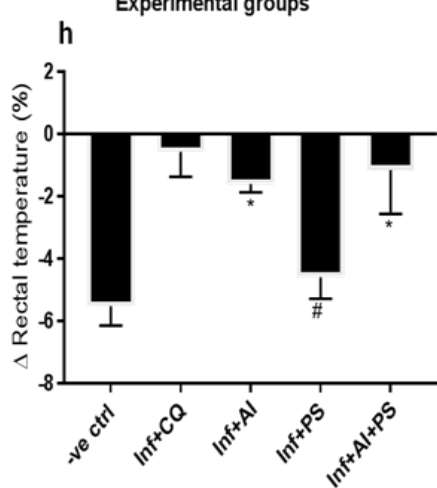

Experimental groups
PROPHYLACTIC

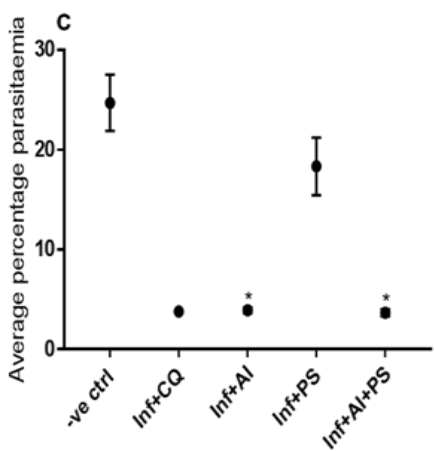

Experimental groups

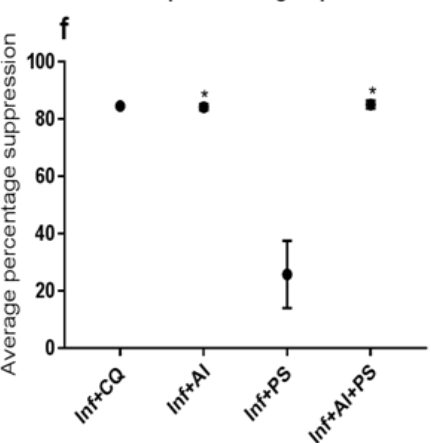

Experimental groups

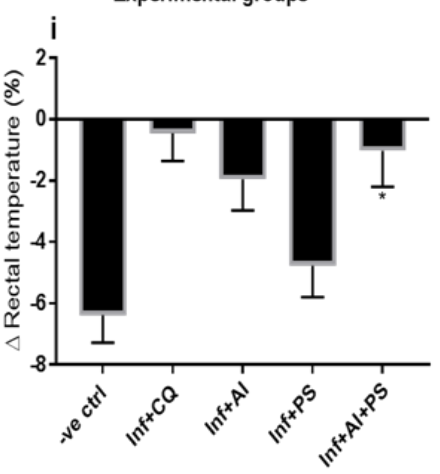

Experimental groups

Figure 1. Average percentage parasitemia; curative (a), suppressive (b), and prophylactic (c), average percentage suppression; curative (d), suppressive (e), and prophylactic (f), percentage $\Delta$ in rectal temperature; curative (g), suppressive (h), and prophylactic (i). -ve ctrl-malarous dams untreated, inf + CQ-malarous dams treated with chloroquine, inf + AI-malarous dams treated with A. indica, inf + PS-malarous dams treated with pear seeds, inf + AI + PS—-malarous dams treated with $A$. indica and pear seeds. * - no significant difference $(p<0.05)$ with the chloroquine-treated malarous dams, \#-no significant difference with untreated malarous dams.

In Table 3, the untreated malarous dams produced an average of 9 pups, where $50 \%$ of these pups were stillborn with a significantly lower crown rump length and birth weight compared to the baseline and treated malarous dams. All the malarous dams treated with either AI, PS, or the combination showed a comparable total number of pups with the noninfected rats (12 pups), while only the infected rats treated with AI produced an equivalent number of still born rats (1 pup) compared to the CQ-treated rats. Infected rats treated with AI and when combined with PS produced pups with higher birth weights than CQ-treated rats but were statistically comparable to the baseline values. No significant differences were found in the time taken for fur appearance in the pups across the study groups. The pups delivered by the infected rats treated with AI and AI + PS recorded a significantly greater crown rump length than both the CQ-treated dams and the non-infected rats. 
Table 3. Litter characteristics of pups from malarous dams in the study groups.

\begin{tabular}{|c|c|c|c|c|c|c|c|}
\hline Groups & $\begin{array}{l}\text { Total No. of } \\
\text { Pups }\end{array}$ & $\begin{array}{c}\text { No. of Live } \\
\text { Pups }\end{array}$ & $\begin{array}{l}\text { No. of Still } \\
\text { Born }\end{array}$ & $\begin{array}{c}\text { Av. Pup } \\
\text { Weight (g) }\end{array}$ & $\begin{array}{c}\text { Eye Opening } \\
\text { (Days) }\end{array}$ & $\begin{array}{l}\text { Appearance } \\
\text { of Fur (Days) }\end{array}$ & $\begin{array}{l}\text { Crown Rump } \\
\text { Length (cm) }\end{array}$ \\
\hline Baseline & 12.0 & 11.0 & 1.0 & $3.6 \pm 0.2$ & $15.0 \pm 1.0$ & $5.6 \pm 0.8$ & $3.3 \pm 0.1$ \\
\hline -ve ctrl & $9.2 \pm 1.4^{b}$ & $4.6 \pm 1.1^{b}$ & $4.6 \pm 0.8^{b}$ & $2.5 \pm 0.2^{b}$ & $15.0 \pm 0.7^{\mathrm{a}}$ & $5.6 \pm 0.8$ & $2.6 \pm 0.1^{b}$ \\
\hline $\operatorname{Inf}+\mathrm{CQ}$ & $12.4 \pm 1.1$ & $11.4 \pm 1.1$ & $1.0 \pm 0.2$ & $3.1 \pm 0.2$ & $15.0 \pm 1.0$ & $6.0 \pm 0.7$ & $3.3 \pm 0.1^{b}$ \\
\hline $\operatorname{Inf}+\mathrm{AI}$ & $12.0 \pm 1.8^{a}$ & $10.8 \pm 1.3^{a}$ & $1.2 \pm 0.2^{\mathrm{a}}$ & $3.9 \pm 0.3^{c}$ & $15.0 \pm 0.7^{\mathrm{a}}$ & $5.4 \pm 0.5$ & $4.1 \pm 0.2$ \\
\hline Inf + PS & $11.8 \pm 0.8^{\mathrm{a}}$ & $9.4 \pm 1.6^{\mathrm{a}}$ & $2.4 \pm 0.4$ & $2.8 \pm 0.1^{\mathrm{a}}$ & $15.2 \pm 0.8^{a}$ & $5.6 \pm 0.8$ & $3.2 \pm 0.2^{\mathrm{a}}$ \\
\hline $\mathrm{Inf}+\mathrm{AI}+\mathrm{PS}$ & $12.6 \pm 1.1^{\mathrm{a}}$ & $10.6 \pm 1.6^{a}$ & $2.0 \pm 0.5$ & $3.9 \pm 0.1^{\mathrm{c}}$ & $14.8 \pm 0.8^{a}$ & $5.8 \pm 0.8$ & $4.1 \pm 0.2$ \\
\hline
\end{tabular}

-ve ctrl-malarous dams untreated, inf $+\mathrm{CQ}$-malarous dams treated with chloroquine, inf + AI-malarous dams treated with $A$. indica, inf + PS - malarous dams treated with pear seeds, inf + AI + PS - malarous dams treated with A. indica and pear seeds, ${ }^{\mathrm{a}}$-no significant difference $(p<0.05)$ with the chloroquine-treated malarous dams, ${ }^{b}$-Significantly lower than baseline, ${ }^{c}$ - significantly higher than the CQ-treated group but comparable to baseline.

The lipid profile of pregnant rats infected with the P. falciparum parasite and either left untreated or treated with CQ, AI, PS, or AI + PS is shown in Table 4. The total cholesterol (TC) and triglyceride (TG) and low-density lipoprotein (LDL) levels of the malarous dams were significantly higher than those of the non malarous dams. The TC, TG, and LDL levels of malarous dams treated with PS or when combined with AI were comparable to the baseline, while the malarous dams treated with either CQ or AI showed significantly higher TC and TG compared to the baseline levels. No significant differences were observed between the individual HDL levels of the treatment groups and baseline. The cardiac risk ratio (CRR) and atherogenic coefficient $(\mathrm{AC})$ of the untreated malarous dams were significantly higher than the non-malarous dams. Chloroquine slightly lowered the CRR levels of the malarous dams when compared to the untreated dams but were significantly higher than the baseline levels. The malarous dams treated with AI, PS, and AI + PS showed comparable CRR and AC levels with the baseline values.

Table 4. Lipid profile of malarous and non malarous dams in the study groups.

\begin{tabular}{|c|c|c|c|c|c|c|}
\hline Groups & $\begin{array}{c}\text { TC } \\
(\mathrm{mg} / \mathrm{dl})\end{array}$ & $\begin{array}{c}\text { TG } \\
(\mathrm{mg} / \mathrm{dl})\end{array}$ & $\begin{array}{c}\text { LDL } \\
(\mathrm{mg} / \mathrm{dl})\end{array}$ & $\begin{array}{c}\text { HDL } \\
(\mathrm{mg} / \mathrm{dl})\end{array}$ & CRR & $\mathrm{AC}$ \\
\hline -ve ctrl & $92.7 \pm 5.2$ & $70.0 \pm 4.9$ & $62.0 \pm 6.4$ & $16.6 \pm 2.0$ & $5.64 \pm 0.8$ & $4.64 \pm 0.8$ \\
\hline $\operatorname{Inf}+\mathrm{CQ}$ & $83.6 \pm 6.9$ & $55.8 \pm 5.5$ & $45.3 \pm 7.8$ & $27.1 \pm 2.5^{c}$ & $3.10 \pm 0.4$ & $2.10 \pm 0.4$ \\
\hline $\operatorname{Inf}+\mathrm{AI}$ & $80.1 \pm 5.0^{a}$ & $54.1 \pm 5.7^{c}$ & $39.1 \pm 3.5^{\mathrm{a}}$ & $30.1 \pm 4.0^{c}$ & $2.68 \pm 0.2^{b}$ & $1.68 \pm 0.2^{b}$ \\
\hline Inf + PS & $65.9 \pm 4.3^{b}$ & $56.5 \pm 5.6^{c}$ & $25.2 \pm 7.4^{b}$ & $29.3 \pm 3.7^{c}$ & $2.29 \pm 0.4^{b}$ & $1.29 \pm 0.4^{b}$ \\
\hline $\mathrm{Inf}+\mathrm{AI}+\mathrm{PS}$ & $72.7 \pm 6.6^{b}$ & $58.6 \pm 5.1^{c}$ & $31.4 \pm 7.1^{b}$ & $29.5 \pm 2.6^{c}$ & $2.47 \pm 0.3^{b}$ & $1.47 \pm 0.3^{b}$ \\
\hline Baseline & $70.4 \pm 5.0$ & $57.2 \pm 6.6$ & $28.1 \pm 8.8$ & $30.8 \pm 4.3$ & $2.32 \pm 0.3$ & $1.32 \pm 0.3$ \\
\hline
\end{tabular}

-ve ctrl-malarous dams untreated, inf + CQ-malarous dams treated with chloroquine, inf + AI-malarous dams treated with $A$. indica, inf + PS—-malarous dams treated with pear seeds, inf + AI + PS—malarous dams treated with A. indica and pear seeds, baseline-non malarous rats, ${ }^{\text {a }}$-no significant difference $(p<0.05)$ with the chloroquinetreated malarous dams, ${ }^{b}$ —no significant difference with the non malarous dams, ${ }^{c}$-no significant difference with both the chloroquine-treated malarous dams and non malarous dams. TC-total cholesterol, TG-triglycerides, HDL-high-density lipoprotein cholesterol, LDL-low-density lipoproteins cholesterol, CRR-cardiac risk ratio, AC-atherogenic coefficient.

The correlations between the average percentage parasitemia and creatinine kinase, lactate dehydrogenase, and cardiac troponin are demonstrated in Figure 2a, Figure 2c, and Figure 2e, respectively, while the mean creatinine kinase, lactate dehydrogenase, and cardiac troponin levels of the experimental animals are shown in Figure 2b, Figure $2 d$, and Figure $2 \mathrm{f}$, respectively. A statistically significant strong positive correlation was found between the average percentage parasitemia and creatinine kinase $(p<0.0001$, $\mathrm{r}=0.7371)$, lactate dehydrogenase $(p<0.0001, \mathrm{r}=0.6555)$, and cardiac troponin $(p<0.0001$, $r=0.7602$ ) of the test groups. The result in Figure $2 b$ shows that the creatinine kinase levels of the untreated malarous dams were significantly elevated during the late trimester. Treatment of the malarous dams using any of CQ, AI, PS, and AI + PS produced equivalent creatinine kinase, lactate dehydrogenase, and cardiac troponin levels when compared with the baseline. 

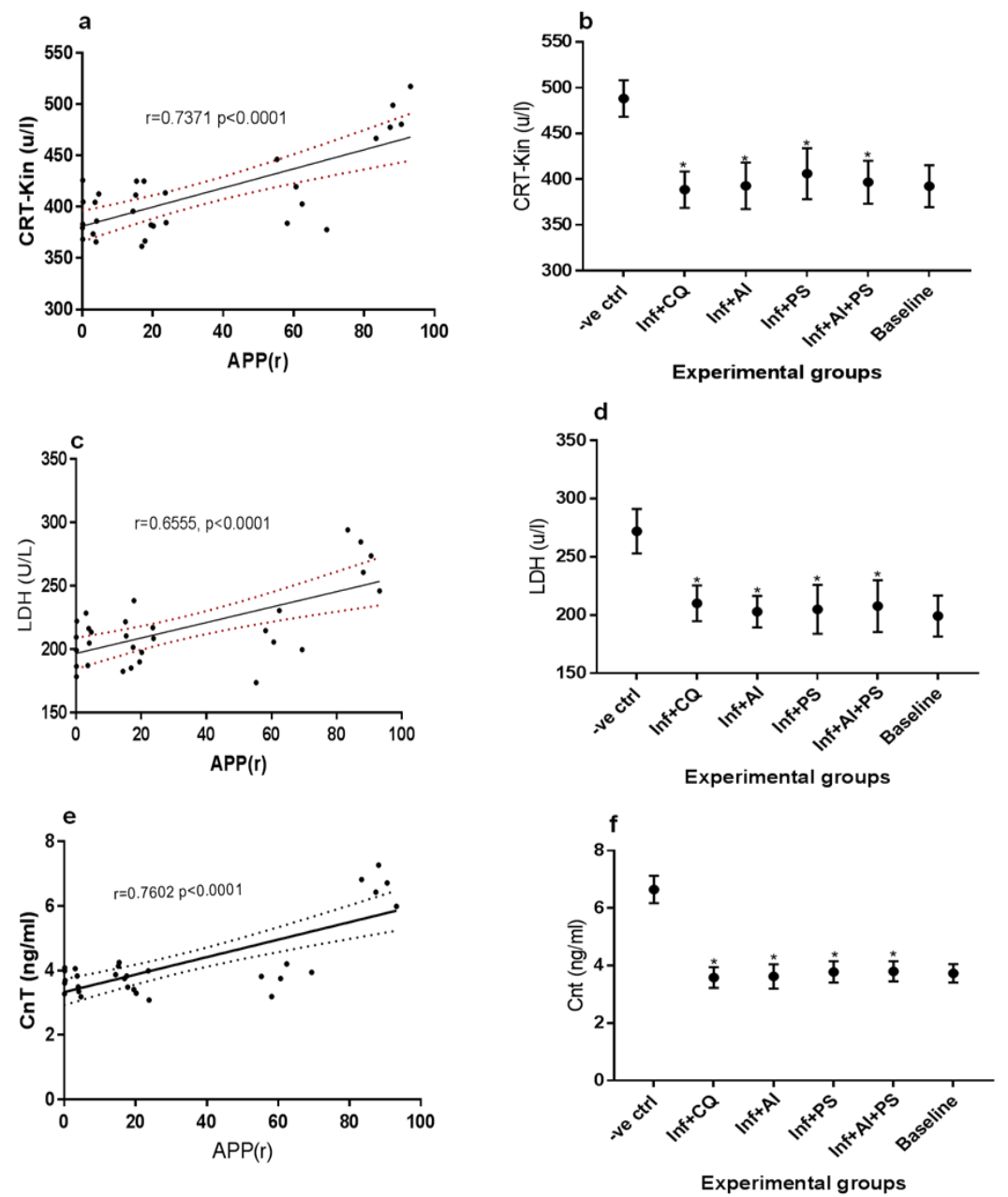

Figure 2. (a) Correlation between Average Percentage Parasitemia Rane's (APP(r)) vs. creatinine kinase (Crt-Kin), (b) mean creatinine kinase levels of malarous and non malarous dams in the study groups, (c) Correlation between Average Percentage Parasitemia Rane's (APP(r)) vs. lactate dehydrogenase (LDH), (d) mean lactate dehydrogenase levels of malarous and non malarous dams in the study groups, (e) Correlation between Average Percentage Parasitemia Rane's (APP(r)) vs. cardiac troponin (CnT), (f) mean cardiac troponin levels of malarous and non malarous dams in the study groups. -ve ctrl-malarous dams untreated, inf + CQ-malarous dams treated with chloroquine, inf + AI-malarous dams treated with A. indica, inf + PS-malarous dams treated with pear seeds, inf + AI + PS-malarous dams treated with $A$. indica and pear seeds, baseline-non malarous rats, *-no significant difference $(p<0.05)$ with the non malarous dams.

The markers of preeclampsia were examined at the third trimester in the malarous dams and are reported in Figure 3a-f. The correlation between the average percentage parasitemia and soluble Fms-Like Tyrosine Kinase-1 (sFlt-1) is shown Figure 3a, while the mean sFlt- 1 levels of the experimental animals are shown in Figure $3 \mathrm{~b}$. A statistically significant $(p<0.0001)$ positive correlation $(r=0.033)$ was found between the average percentage parasitemia and sFlt-1 levels. The mean sFlt-1 levels of the untreated malarous dams were significantly elevated prior to delivery while the malarous dams treated with bot AI and CQ showed slightly decreased sFlt-1 levels but were not comparable to the baseline levels. The malarous dams treated with PS or in combination with AI showed no significant difference in their sFlt-1 levels when compared with the non-malarous dams. Figure $3 c$ showed a statistically significant $(p<0.0001)$ strong negative correlation $(\mathrm{r}=-0.6955)$ between the average percentage parasitemia and placental growth factor (PIGF). The result for the mean PIGF levels of the experimental animals presented in Figure $3 \mathrm{~d}$ showed that the untreated malarous dams recorded significantly decreased PIGF 
when compared to the non-malarous dams. The malarous dams treated with $\mathrm{CQ}, \mathrm{AI}$, and PS significantly increased the PIGF levels but were not comparable to the baseline levels, while the malarous dams treated with a combination of AI and PS showed no significant difference in the PIGF levels compared to the baseline. A strong positive correlation $(r=0.6373)$ was observed between the average percentage parasitemia and ratio of sFlt-1 and PIGF (Figure 3e). The untreated malarous dams showed significantly elevated mean sFlt-1/PIGF levels while the malarous dams treated with CQ, AI, or PS showed significantly lower mean sFlt-1/PIGF levels when compared to the untreated malaria rats. The malarous dams placed on combinatorial administration of AI and PS showed mean sFlt-1/PIGF levels equivalent to the baseline levels.
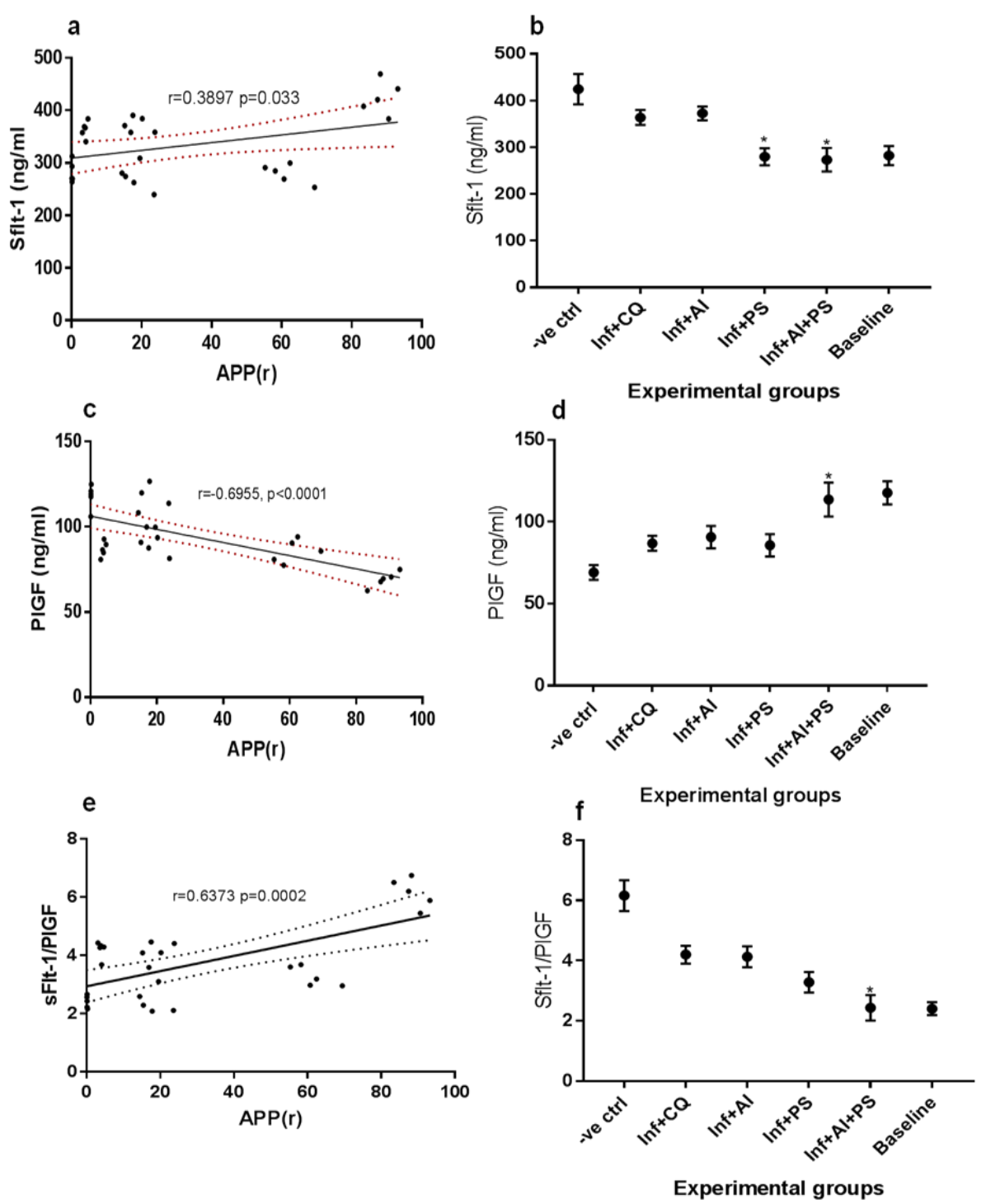

Figure 3. (a) Correlation between Average Percentage Parasitemia Rane's (APP(r)) vs. soluble Fms-Like Tyrosine Kinase-1 (sFlt-1), (b) mean sFlt-1 levels of malarous and non malarous dams in the study groups, (c) Correlation between Average Percentage Parasitemia Rane's (APP(r)) vs. Placental growth factor (PIGF), (d) mean PIGF levels of malarous and non malarous dams in the study groups, (e) Correlation between Average Percentage Parasitemia Rane's (APP(r)) vs. ratio of sFlt-1 and PIGF, (f) mean sFlt-1/PIGF levels of malarous and non malarous dams in the study groups. -ve ctrl-malarous dams untreated, inf + CQ-malarous dams treated with chloroquine, inf + AI-malarous dams treated with A. indica, inf + PS-malarous dams treated with pear seeds, inf + AI + PS-malarous dams treated with A. indica and pear seeds, baseline-non malarous rats, *-no significant difference $(p<0.05)$ with the baseline. 


\section{Discussion}

The present study was conducted on P. falciparum-parasitized rat models to evaluate the potency and maternal effects of a popular antimalarial herb (Azadirachta indica combined with $D$. edulis seeds) used in real life in areas of high malaria endemicity in Nigeria. Preliminary findings revealed that the feed intake, maternal weight, and placenta weight at birth were all adversely affected by malaria-in-pregnancy. Appetite loss was restored in rats treated with AI and in combination with PS. According to Ndyomugyenyi et al. [26], loss of appetite is one of the major diagnostic symptoms of malaria, which in this study explains the significant decrease in the feed intake and consequent weight loss of the untreated malarous dams. Maternal undernutrition is a serious risk factor for fetal undernutrition that causes changes in fetal structure and physiology and consequently, low birth weight [27]. A. indica, similar to the effects of chloroquine, improved the feed intake of the malarous pregnant rats, which led to the improvement of maternal weight during malariain-pregnancy. In agreement with the findings of this study, earlier reports associated weight gain with the administration of $A$. indica [28]; however, there is scarce literature on the effect of AI on appetite and feed intake during gestational malaria. Our study further showed that $P$. falciparum infection caused a significant decrease in placental weight. The placental weight at birth represents an important clinical parameter that determines pregnancy outcomes [29]. Several complications of maternal health are associated with low placental weight, including chronic hypertension and preeclampsia [30], and anemia [31]. Thus, the restoration of placental weight after treatment with $A$. indica is indicative of a possible efficacy in malaria-induced preeclamptic conditions. Further, the $A$. indica leaves, when administered as a prophylactic and suppressive agent against $P$. falciparum in the pregnant rats, achieved a therapeutic efficacy of $97 \%$ but slightly lesser when combined with pear seeds. This puts the potency of $A$. indica above the 33 African antimalarial herbs screened for their antiplasmodial effects [32] and within the 93\% recommendations of World Health Organization (WHO) for cure rates of antimalarial drugs. Results obtained from the rectal thermometry also validated both the blood schizontocidal activities of $A$. indica especially in combination with pear seeds, as well as their potent antipyretic effect, having showed a hypothermic effect on the malarous dams. Additionally, the malarous dams compared to the non malarous dams showed symptoms of preeclampsia with an elevation of blood pressure, heartbeat rate, and urine excretion. The exclusive treatment with $A$. indica normalized both the systolic and diastolic blood pressure but showed slight efficacy in reversing an altered heartbeat and polyuria. From the findings, the practice of combining $A$. indica and pear seeds by traditional healers proves more effective in ameliorating the altered markers of malaria-induced hypertension, both of which are established symptoms of gestational malaria $[33,34]$. The malarous dams also showed symptoms of thrombocytopenia, which has become an established symptom and a considered prognostic factor of severe gestational malaria [35-37]. The administration of $A$. indica and in combination with $D$. edulis seeds led to about a $47 \%$ increase in the platelet count during the malarous pregnancy. This may be due to the reported thrombocytosis associated with the administration of $A$. indica [38]. Results from the litter characteristics further indicated that $A$. indica could complement present malaria control programs in averting poor pregnancy outcomes, fetal mortality, and low birth weight associated with malaria-in-pregnancy. The infected but untreated rats recorded about $50 \%$ fetal wastages when compared to the rats treated with $A$. indica, pear seeds, or the combination. The treatment with exclusive $A$. indica produced the least number of still born pups compared to other interventions and compared to non-malarous pregnancies. The herbs administered prevented the occurrence of low birth weight in the malarous dams, which were significantly higher than chloroquine-treated rats. Birth weight is an important primary endpoint in measuring the success of interventions during gestational malaria, with low birth weight an outcome of unsuccessful interventions. With this, A. indica could be considered for its overall improvement of pregnancy outcomes during gestational malaria. Additionally, from the crown rump lengths of the fetus, the interventions possibly averted malaria-induced intrauterine growth restriction. 
The untreated infected dams produced fetuses with significantly lower crown rump length by up to $0.6 \mathrm{~cm}$, which depicted severe fetal growth restriction during gestational malaria. This result raises the suspicion that the bioactive components of the test herbs permeate the placental-fetal membrane barrier to enhance fetal well-being. Further cardiovascular involvements during malaria-in-pregnancy were highlighted by our findings. The lipid profile of the malarous dams implied that severe hypercholesterolemia was a consequence of untreated gestational malaria and the hypercholesterolemic effect persisted even after chloroquine treatment. In agreement with our finding, earlier studies established that patients with malaria present clinical conditions, such as hypocholesterolemia, hypertriglyceridemia, and low levels of high-density lipoproteins (HDLs) and low-density lipoproteins (LDLs) [39]. Hence, the therapeutic efficacy of the antimalarial herbs decreased the susceptibility of the malarous pregnant rats' to cardiovascular dysfunction. In support of these findings, creatine kinase and lactate dehydrogenase and cardiac troponin, which are all established biomarkers of preeclampsia [40-42], were all significantly elevated in untreated gestational malaria, whereas they were significantly lowered to baseline levels in all the treatment groups. These elevated peptides affirm a previous suspicion that malaria-in-pregnancy predisposes to hypertensive disorders especially during the late trimester. Due to the established specificity of these peptides for cardiac tissue, it is safe to assume that some degree of myofibrillary damage occurred in association with malaria-inpregnancy. These claims of preeclampsia resulting from gestational malaria in this study are supported by the strong correlation between the percentage parasitemia and other secondary outcome measurements like the soluble Fms-Like Tyrosine Kinase-1 (sFlt-1) and placental-induced growth factor (PIGF). sFlt-1 is a placenta-derived antiangiogenic protein regarded as a reliable diagnostic marker for preeclampsia [43]. The sFLT-1 was over-secreted during the late-stage trimester in the malarous dams and neither chloroquine nor $A$. indica exclusively administered reversed this outcome. However, pear seed either exclusively administered or in combination with $A$. indica normalized the altered sFlt- 1 in the malarous dams. Hence, D. edulis pear seed, similar to its vasoprotective effects [16], could be regarded as a potent herb for the management of malaria-induced preeclampsia. This clearly justifies, pending clinical trials, the rationale behind the inclusion of pear seeds as part of the traditional treatment protocol for malaria in poor-resource settings. Similar to sFlt-1, PlGF is a key molecule in angiogenesis and vasculogenesis during embryogenesis with a reliable predictive performance during preeclampsia diagnosis [44]. Furthermore, the ratio of sFLT-1 and PIGF is regarded as a more economic and reliable indicator for preeclampsia and severity rather than individual interpretations [45-47]. Hence, the reversal of altered levels of sFlt-1/PIGF clearly supports a combinatorial administration as most effective in the management of malaria-in-pregnancy-induced preeclampsia. From the findings of this study, it is possible to hypothesize that the exclusive administration of the antimalarial drugs is less effective in mitigating the malaria-induced preeclampsia and does require supplementation with vasomodulatory agents for effective treatment of gestational malaria-induced hypertensive disorders. However, an important limitation to acknowledge in this study is the lack of data on the effect of this therapy on placenta oxidation markers. We recommend that future studies should examine if these herbal remedies modulate placenta oxidation during preeclampsia to add further credibility to the efficacy of these therapies to ameliorate malaria-induced preeclampsia.

\section{Conclusions}

The popular practice of using A. indica, and in some cases combining it with antihypertensive herbs like pear seeds, during malaria-in-pregnancy may be justified given the findings of this study. Early indicators of pregnancy outcomes including maternal and placental weight were effectively restored after alterations in the P. falciparum-infected dams. The percentage parasitemia obtained with treatment with $A$. indica was comparable to the standard drugs and attained the $93 \%$ recommended cure rates by the World Health Organization. In addition, elevated blood pressure, heartbeat rates, and thrombocytopenia 
found in untreated malaria-in-pregnancy were reversed with combinatorial administration of $A$. indica and the pear seeds. The use of $A$. indica as antimalarial therapy minimized fetal deaths and showed similar birth weights to non-malarous dams, and by combining A. indica with pear seeds, the resulting biomarkers of preeclampsia and cardiovascular dysfunction in the malarous dams were effectively normalized.

Author Contributions: Conceptualization, P.U.A.; Data curation, P.U.A., C.N.U., J.A.A. and C.G.N.; Formal analysis, P.U.A., U.C.N. and C.G.N.; Funding acquisition, E.N.A.; Investigation, P.U.A., C.N.U., J.A.A. and C.G.N.; Methodology, E.N.A., C.N.U., U.C.N., J.A.A. and C.G.N.; Project administration, P.U.A. and C.G.N.; Resources, P.U.A.; Supervision, P.U.A., E.N.A., C.N.U. and U.C.N.; Validation, P.U.A., E.N.A. and J.A.A.; Writing—original draft, P.U.A.; Writing—review \& editing, P.U.A., E.N.A., C.N.U., U.C.N., J.A.A. and C.G.N. All authors have read and agreed to the published version of the manuscript.

Funding: This research received no external funding.

Institutional Review Board Statement: The study was conducted according to the guidelines of the Declaration of Helsinki, and approved by the Institutional Review Board of the Imo State University, sitting in the Department of Biochemistry (IMSU/BCM/ETS/20181212 and 12 December 2018).

Informed Consent Statement: Informed consent was obtained from all subjects involved in the study.

Data Availability Statement: Data is available with reasonable request made to the corresponding author.

Conflicts of Interest: No conflict of interest regarding this study.

\section{References}

1. Boutayeb, A. The Burden of and Non-Communicable Diseases in Developing Countries. In Handbook of Disease Burdens and Quality of Life Measures; Springer: New York, NY, USA, 2010; pp. 531-546.

2. Gajida, A.U.; Iliyasu, Z.; Zoakah, A.I. Malaria among antenatal clients attending primary health care facilities in Kano State, Nigeria. Ann. Afr. Med. 2010, 9, 188-193. [CrossRef] [PubMed]

3. Onwujekwe, O.; Uguru, N.; Etiaba, E.; Chikezie, I.; Uzochukwu, B.; Adjagba, A. The Economic Burden of Malaria on Households and the Health System in Enugu State Southeast Nigeria. PLOS ONE 2013, 8, e78362.

4. Bhalla, D.; Cleenewerck, L.; Okorafor Kalu, S.; Abubakar Gulma, K. Malaria Prevention Measures among Pregnant Women: A Population-Based Survey in Nnewi, Nigeria. Sci. World J. 2019, 2019, 6402947. [CrossRef] [PubMed]

5. World Health Organization. The World Malaria Report 2019 at a Glance; Regional and Global Trends in Burden of Malaria Cases and Deaths. 2019. Available online: https://www.who.int/news-room/feature-stories/detail/world-malaria-report-2019 (accessed on 30 July 2021).

6. Okafor, I.P.; Ezekude, C.; Oluwole, E.O.; Onigbogi, O.O. Malaria in pregnancy: A community-based study on the knowledge, perception, and prevention among Nigerian women. J. Family Med. Prim. Care 2019, 8, 1359-1364. [CrossRef] [PubMed]

7. Sam-Wobo, S.O.; Akinboroye, T.; Anosike, J.C.; Adewale, B. Knowledge and practices on malaria treatment measures among pregnant women in Abeokuta, Nigeria. Tanzan. J. Health Res. 2008, 10, 226-231. [PubMed]

8. Chidinma, E.I.; Duru, A.C.; Ingwu, J.A.; Arinze, J.C.; Chikeme, P.C.; Kotoye, C.O. Use of traditional medicines in treatment of malaria among pregnant women in two urban slums in Enugu State, Nigeria. J. Public Health Dis. 2019, 30, $24-31$.

9. Khalid, S.A.; Farouk, A.; Geary, T.G.; Jensen, J.B. Potential antimalarial candidates from African plants: An in vitro approach using Plasmodium falciparum. J. Ethnopharmacol. 1986, 15, 201-209. [CrossRef]

10. Phillipson, J.D.; Wright, C.W. Can ethnopharmacology contribute to the development of antimalarial agents? J. Ethnopharmacol. 1991, 32, 155-165. [CrossRef]

11. Leaman, D.J.; Arnason, J.T.; Yusuf, R.; Sangat-Roemantyo, H.; Soedjito, H.; Angerhofer, C.K.; Pezzuto, J.M. Malaria remedies of the Kenyah of the Apo Kayan, East Kalimantan, Indonesian Borneo: A quantitative assessment of local consensus as an indicator of biological efficacy. J. Ethnopharmacol. 1995, 49, 1-16. [CrossRef]

12. Priyadarsini, R.V.; Manikandan, P.; Kumar, G.H.; Nagini, S. The neem limonoids azadirachtin and nimbolide inhibit hamster cheek pouch carcinogenesis by modulating xenobiotic-metabolizing enzymes, DNA damage, antioxidants, invasion and angiogenesis. Free Radic. Res. 2009, 43, 492-504. [CrossRef]

13. Alzohairy, M.A. Therapeutics Role of Azadirachta indica (Neem) and Their Active Constituents in Diseases Prevention and Treatment. Evid.-Based Complement. Alternat. Med. 2016, 2016, 7382506. [CrossRef]

14. MacKinnon, S.; Durst, T.; Arnason, J.T.; Angerhofer, C.; Pezzuto, J.; Sanchez-Vindas, P.E.; Poveda, L.J.; Gbeassor, M. Antimalarial activity of tropical Meliaceae extracts and gedunin derivatives. J. Nat. Prod. 1997, 60, 336-341. [CrossRef]

15. Rochanakij, S.; Thebtaranonth, Y.; Yenjai, C.; Yuthavong, Y. Nimbolide, a constituent of Azadirachta indica, inhibits Plasmodium falciparum in culture. Southeast Asian J. Trop. Med. Public Health. 1985, 16, 66-72. 
16. Amadi, P.U.; Agomuo, E.N.; Adumekwe, C.W. Modulatory properties of cardiac and quercetin glycosides from Dacryodes edulis seeds during L-NAME-induced vascular perturbation. J. Basic Clin. Physiol. Pharmacol. 2020, 31, 1-8. [CrossRef] [PubMed]

17. Amadi, P.U.; Agomuo, E.N.; Bob-Chile Agada, A.; Njoku, U.C.; Ifeanacho, M.O.; Okereke, C.J.; Iheka, C.U.; Osuoha, J.O. Toxicities selected medicinal plants, and floras of lower phyla. Alex. J. Med. 2018, 54, 587-596. [CrossRef]

18. Xie, L.H.; Johnson, T.O.; Weina, P.J.; Si, Y.; Haeberle, A.; Upadhyay, R.; Wong, E.; Li, Q. Risk assessment and therapeutic indices of artesunate and artelinate in Plasmodium berghei-infected and uninfected rats. Int. J. Toxicol. 2005, 24, 251-264. [CrossRef]

19. Shu, W.; Li, H.; Gong, H.; Zhang, M.; Niu, X.; Ma, Y.; Zhang, X.; Cai, W.; Yang, G.; Wei, M.; et al. Evaluation of blood vessel injury, oxidative stress and circulating inflammatory factors in an L-NAME-induced preeclampsia-like rat model. Exp. Ther. Med. 2018, 16, 585-594. [CrossRef] [PubMed]

20. Ryley, J.; Peters, W. The antimalarial activity of some quinolone esters. Ann. Trop. Med. Parasitol. 1970, 64, 209-222. [CrossRef] [PubMed]

21. Peters, W. The four-day suppressive in vivo antimalarial test. Ann. Trop. Med. Parasitol. 1975, 69, 155-171. [CrossRef]

22. Peters, W. Drug resistance in Plasmodium bergheiVincke and lips, 1948. I. Chloroquine resistance. Exp. Parasitol. 1965, 17, 80-89. [CrossRef]

23. Peters, W.; Robinson, B. The chemotherapy of rodent malaria. XLVII. Studies on pyronaridine and other Mannich base antimalarials. Ann. Trop. Med. Parasitol. 1992, 86, 455-465. [CrossRef]

24. Agomuo, E.N.; Amadi, P.U.; Adumekwe, C.W. Gestational geophagia affects nephrocardiac integrity, ATP-driven proton pumps, renin-angiotensin-aldosterone system and F2-isoprostane status. Med. Sci. 2019, 7, 13. [CrossRef] [PubMed]

25. Horder, M.; Elser, R.C.; Gerhardt, W.; Matthieu, M.; Sampson, E.J. Approved recommendation on IFCC methods for the measurement of catalytic concentration of enzymes. Part 7. IFCC method for creatine kinase (ATP: Creatine N-phosphotransferase, EC 2.7.3.2). Eur. J. Clin. Chem. Clin. Biochem. 1991, 29, 435-456.

26. Ndyomugyenyi, R.; Magnussen, P.; Clarke, S. Diagnosis and treatment of malaria in peripheral health facilities in Uganda: Findings from an area of low transmission in south-western Uganda. Malar. J. 2007, 6, 39. [CrossRef]

27. Fall, C.H. Fetal malnutrition and long-term outcomes. In Maternal and Child Nutrition: The First 1000 Days; Bhatia, J., Bhutta, Z.A., Kalhan, S.C., Eds.; Karger Publishers, Basel, Switzerland: 2013; Volume 74, pp. 11-25.

28. Ashafa, A.O.; Orekoya, L.O.; Yakubu, M.T. Toxicity profile of ethanolic extract of Azadirachta indica stem bark in male Wistar rats. Asian Pac. J. Trop. Biomed. 2012, 2, 811-817. [CrossRef]

29. Panti, A.A.; Ekele, B.A.; Nwobodo, E.I.; Yakubu, A. The relationship between the weight of the placenta and birth weight of the neonate in a Nigerian Hospital. Niger. Med. J. 2012, 53, 80-84. [CrossRef]

30. McNamara, H.; Hutcheon, J.A.; Platt, R.W.; Benjamin, A.; Kramer, M.S. Risk factors for high and low placental weight. Paediatr. Perinat. Epidemiol. 2014, 28, 97-105. [CrossRef] [PubMed]

31. Baptiste-Roberts, K.; Salafia, C.M.; Nicholson, W.K.; Duggan, A.; Wang, N.Y.; Brancati, F.L. Maternal risk factors for abnormal placental growth: The national collaborative perinatal project. BMC Pregnancy Childbirth 2008, 8, 44. [CrossRef] [PubMed]

32. Zirihi, G.N.; Mambu, L.; Guédé-Guina, F.; Bodo, B.; Grellier, P. In vitro antiplasmodial activity and cytotoxicity of 33 West African plants used for treatment of malaria. J. Ethnopharmacol. 2005, 98, 281-285. [CrossRef]

33. Zaki, S.A.; Shanbag, P. Increased urinary frequency: An unusual presentation of Plasmodium falciparum malaria. Saudi J. Kidney Dis. Transpl. 2012, 23, 844-845. [CrossRef] [PubMed]

34. Rulisa, S.; Kaligirwa, N.; Agaba, S.; Karangayire, P.; Mens, P.F.; de Vries, P.J. Fetal and maternal hemodynamics in acute malaria during pregnancy. Int. J. Gynaecol. Obstet. 2012, 119, 66-69. [CrossRef] [PubMed]

35. Imbert, P.; Rogier, C.; Gerardin, P. Letter to the editor. Am. J. Trop. Med. Hyg. 2003, 68, 380-381. [CrossRef]

36. Abdalla, S.; Pasvol, G. Platelets and blood coagulation in human malaria. In The Haemotology of Malaria; Newton, P.N., Essien, E., White, N.J., Eds.; Imperial College Press: London, UK, 2004; pp. 249-276.

37. Erhabor, O.; Jeremiah, Z.A.; Adias, T.C.; Hart, M.L. Thrombocytopenia in plasmodium parasitized pregnant women in the Niger Delta of Nigeria. Pathol. Lab. Med. Int. 2010, 2, 1-5.

38. Iyare, E.E.; Obaji, N.N. Effects of aqueous leaf extract of azadirachta indica on some haematological parameters and blood glucose level in female rats. Niger. J. Exp. Clin. Biosci. 2014, 2, 54-58. [CrossRef]

39. Dias, R.M.; Vieira, J.L.; Cabral, B.D.; da Silva, I.R.; Brasil, L.M.; Araújo, E.D.; de Andrade, M.A. Lipid Profile of Children with Malaria by Plasmodium vivax. J. Trop. Med. 2016, 2016, 9052612. [CrossRef]

40. Fleming, S.M.; O'Gorman, T.; Finn, J.; Grimes, H.; Daly, K.; Morrison, J.J. Cardiac troponin I in pre-eclampsia and gestational hypertension. BJOG 2000, 107, 1417-1420. [CrossRef] [PubMed]

41. Jaiswar, S.P.; Gupta, A.; Sachan, R.; Natu, S.N.; Shaili, M. Lactic dehydrogenase: A biochemical marker for preeclampsia-eclampsia. J. Obstet. Gynaecol. India 2011, 61, 645-648. [CrossRef]

42. Horjus, D.L.; Bokslag, A.; Hooijberg, F.; Hutten, B.A.; Middeldorp, S.; de Groot, C.J.M. Creatine kinase and blood pressure in women with a history of early-onset preeclampsia. Pregnancy Hypertens. 2019, 15, 118-122. [CrossRef]

43. Roberts, J.M.; Rajakumar, A. Preeclampsia and soluble fms-like tyrosine kinase 1. J. Clin. Endocrinol. Metab. 2009, 94, 2252-2254. [CrossRef]

44. Agrawal, S.; Shinar, S.; Cerdeira, A.S.; Redman, C.; Vatish, M. Predictive Performance of PlGF (Placental Growth Factor) for Screening Preeclampsia in Asymptomatic Women: A Systematic Review and Meta-Analysis. Hypertension 2019, 74, 1124-1135. [CrossRef] 
45. Zeisler, H.; Llurba, E.; Chantraine, F.; Vatish, M.; Staff, A.C.; Sennström, M.; Olovsson, M.; Brennecke, S.P.; Stepan, H.; Allegranza, D.; et al. Predictive Value of the sFlt-1:PlGF Ratio in Women with Suspected Preeclampsia. N. Engl. J. Med. 2016, 374, 13-22. [CrossRef] [PubMed]

46. Schlembach, D.; Hund, M.; Schroer, A.; Wolf, C. Economic assessment of the use of the sFlt-1/PlGF ratio test to predict preeclampsia in Germany. BMC Health Serv. Res. 2018, 18, 603. [CrossRef] [PubMed]

47. Nikuei, P.; Rajaei, M.; Roozbeh, N.; Mohseni, F.; Poordarvishi, F.; Azad, M.; Haidari, S. Diagnostic accuracy of sFlt1/PlGF ratio as a marker for preeclampsia. BMC Pregnancy Childbirth 2020, 20, 80. [CrossRef] [PubMed] 